\title{
DETERMINATION OF ARSENIC AND SELENIUM IN SURFACE WATER BY ATOMIC ABSORPTION TO SUPPORT ENVIRONMENTAL MONITORING PROGRAMS
}

H. G. King

R. W. Morrow

November 1974

\section{MASTER}

OAK RIDGE Y-12 PLANT

OAK RIDGE. TENNESSEE 


\section{DISCLAIMER}

This report was prepared as an account of work sponsored by an agency of the United States Government. Neither the United States Government nor any agency Thereof, nor any of their employees, makes any warranty, express or implied, or assumes any legal liability or responsibility for the accuracy, completeness, or usefulness of any information, apparatus, product, or process disclosed, or represents that its use would not infringe privately owned rights. Reference herein to any specific commercial product, process, or service by trade name, trademark, manufacturer, or otherwise does not necessarily constitute or imply its endorsement, recommendation, or favoring by the United States Government or any agency thereof. The views and opinions of authors expressed herein do not necessarily state or reflect those of the United States Government or any agency thereof. 


\section{DISCLAIMER}

Portions of this document may be illegible in electronic image products. Images are produced from the best available original document. 

Printed in the United States of America. Available from National Technical Information Service
U.S. Department of Commerce
5285 Port Royal Road, Springfield, Virginia 22151

Price: Printed Copy \$4.00; Microfiche \$1.45

This report was prepared as an account of work sponsored by the United States Government. Neither the United States nor the United States Atomic Energy Commission, nor any of their employees, nor any of their contractors, subcontractors, or their employees, makes any warranty, express or implied, or assumes any legal liability or responsibility for the accuracy, completeness or usefulness of any information, apparatus, product or process disclosed, or represents that its use would not infringe privately owned rights. 


\title{
DETERMINATION OF ARSENIC AND SELENIUM IN SURFACE WATER BY ATOMIC ABSORPTION TO SUPPORT ENVIRONMENTAL MONITORING PROGRAMS
}

\author{
H. G. King \\ Laboratory Development Department \\ Y-12 Development Division \\ and \\ R. W. Morrow \\ Plant Laboratory Department \\ Product Certification Division
}

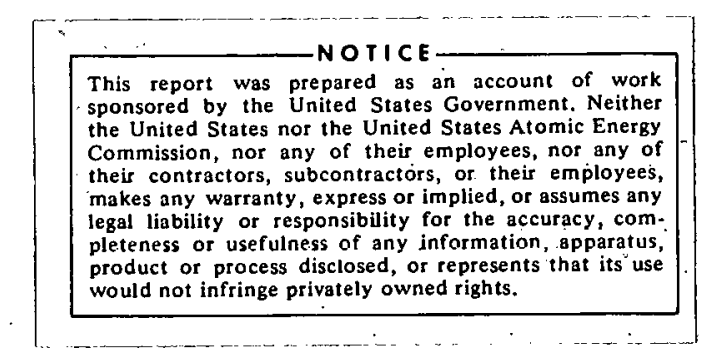

\section{Oak Ridge Y-12 Plant}

P.O. Box Y, Oak Ridge, Tennessee $\mathbf{3 7 8 3 0}$

Prepared for the U.S. Atomic Energy Commission

Undei U.S. Government Contract W./4ubeng-26 


\section{ABSTRACT}

A method has been developed for determining arsenic and selenium in surface water by atomic absorption. The two elements are hydrided in acidified water by sodium borohydride to form arsine and selenine gases, which are then passed into a low-temperature argon/air/hydrogen flame for the atomic absorption measurement. A background correction is made by adjusting the gas flow rates. The limit of detection is $5 \mu \mathrm{g} / \mathrm{l}$ for arsenic and $1 \mu \mathrm{g} / \mathrm{l}$ for selenium. The method is both fast and economical. 


\section{CONTENTS}

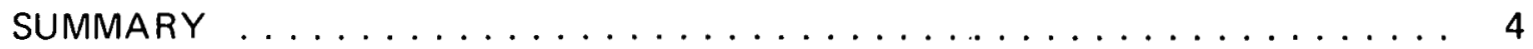

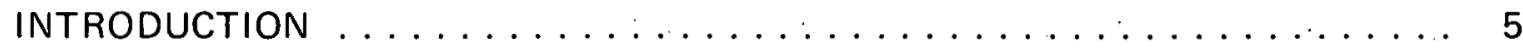

DETERMINATION OF ARSENIC AND SELENIUM $\ldots \ldots \ldots \ldots \ldots \ldots \ldots$

Analytical Procedure ........................ 6

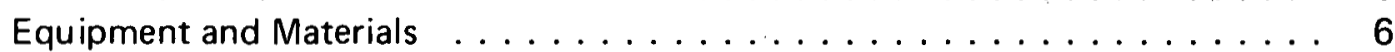

General Considerations ....................... 7

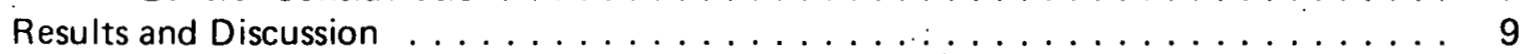




\section{SUMMARY}

Reaction of arsenic and selenium with nascent hydrogen will reduce the two elements to arsine $\left(\mathrm{AsH}_{3}\right)$ and selenine $\left(\mathrm{H}_{2} \mathrm{Se}\right)$ gases which are then mixed with argon and swept into a low-temperature hydrogen flame for atomic absorption measurement. Greatly increased sensitivity (compared to the aspiration of solutions) arises from introducing the gaseous analytes into the hydrogen flame and from the concentration effected by the accumulation of the gas from the $50-\mathrm{ml}$ sample in the hydrider, followed by rapid injection into the burner. Levels of detection and precisions of the results showed the method to be quite suitable for determining arsenic and selenium in environmental water samples. 


\section{IINTRODUCTION}

Both arsenic and selenium are of considerable importance in environmental surveillance. The Plant Laboratory, located at the Oak Ridge Y-12 Plant, (a) furnishes analytical services to various Union Carbide Corporation Nuclear Division groups involved in environmental monitoring. Many of these monitoring activities would be incomplete without an analysis for these two elements.

In choosing the best approach, spectrographic methods were quickly discarded because the strong lines for both arsenic and selenium are in the far ultraviolet region and are not accessible with present instrumentation. Chemical procedures for trace levels of arsenic and selenium are tedious, expensive, and suffer interferences. Atomic absorption spectroscopy appeared to be a more attractive approach, but the usual direct aspiration of water samples provided only relatively high levels of detection and was unsuitable. Furthermore, strong absorption of the ultraviolet arsenic and selenium resoriance lines by hydrocarbon flames results in severe noise levels and low precision. The best approach appeared to be hydriding of the two elements followed by the introduction of the gaseous hydrides into a hydrogen and air flame.

A very sensitive atomic absorption method for detecting and measuring these elements has been described by Fernandez and Manning(b) and Manning, (c) who formed the volatile hydrides of arsenic and selenium and introduced them into an argon/hydrogen/air flame. Fernandez (d) found that sodium borohydride $\left(\mathrm{NaBH}_{4}\right)$ was an effective hydriding agent. The convenience of adding $\mathrm{NaBH}_{4}$ to form $\mathrm{AsH}_{3}$ and $\mathrm{H}_{2} \mathrm{Se}$ makes this the more attractive approach.

(a) Operated by the Union Carbide Corporation's Nuclear Division for the US Atomic Energy Commission.

(b) Fernandez, F. J. and Manning, D. C.; Atomic Absorption Newsletter, 10, p 86 (1971).

(c) Manning, D. C.; Atomic Absorption Newsletter, 10, p 123 (1971).

(d) Fernandez, F. J.; Atomic Absorption News/etter, 12, p 93 (1973). 


\section{DETERMINATION OF ARSENIC AND SELENIUM}

\section{ANALYTICAL PROCEDURE}

\section{Equipment and Materials}

Equipment used in the analysis were:

Perkin-Elmer Model 303 atomic absorption spectrophotometer with a recording attachment and a three-sltot Techtron burner.

Perkin-Elmer selenium spectral lamp.

Perkin-Elmer arsenic spectral lamp.

Minneapolis-Honeywell recorder (10 mv, full scale).

Custom-built hydriding generator $(200-\mathrm{ml}$ capacity).

Magnetic stirrer - speed continuouly adjustable.

Dispenser (2-ml capacity).

Rubber membrane.

Reagents and materials used were:

Hydrochloric acid $(\mathrm{HCl})$ - distilled.

Sodium borohydride ( $\left.\mathrm{NaBH}_{4}\right)$ - arsenic and selenium free (0.2-g pellets).

Argon gas - plant supply.

Hydrogen gas - technical grade.

Demineralized water-made batchwise by passing available plant demineralized water through a small demineralizer.

Tesi salıule - Iavv lieek viater.

The double-beam Model 303 spectrometer was altered for the installation of a Techtron burner with a three-slot head. The burner provides increased sensitivity over the usual single-slot, low-temperature burner and is more stable. Spectrometer amplifier output is fed into the recorder attachment to expand the scale. The recorder has a full-scale response time of 2 seconds, which is satisfactory for the analysis.

Hollow cathode lamps have a slow warmup time, requiring up to an hour for stabilization. During use, the lamps should be closely watched and their spectral power adjusted as necessary.

The hydriding generator was constructed from a flat-bottomed flask with three ground-glass necks. One neck is fitted with an elastic membrane, the gas flush system is fitted into the center neck, and the third neck is used to introduce the sample and the $\mathrm{NaBH}_{4}$ pellet. The flush system has a bypass for use when the generator is not being purged. Wash-water and vacuum drain lines are attached to glass-tube throughputs in the lower section of the flask. Figure 1 gives a view of the hydriding generator and the atomic absorption spectrometer. The generator is detailed in Figure 2.

Arsenic and selenium are common contaminants in laboratory chemicals; therefore, the $\mathrm{HCl}$ used in the procedure should be treated with metallic zinc and distilled. Demineralized water 


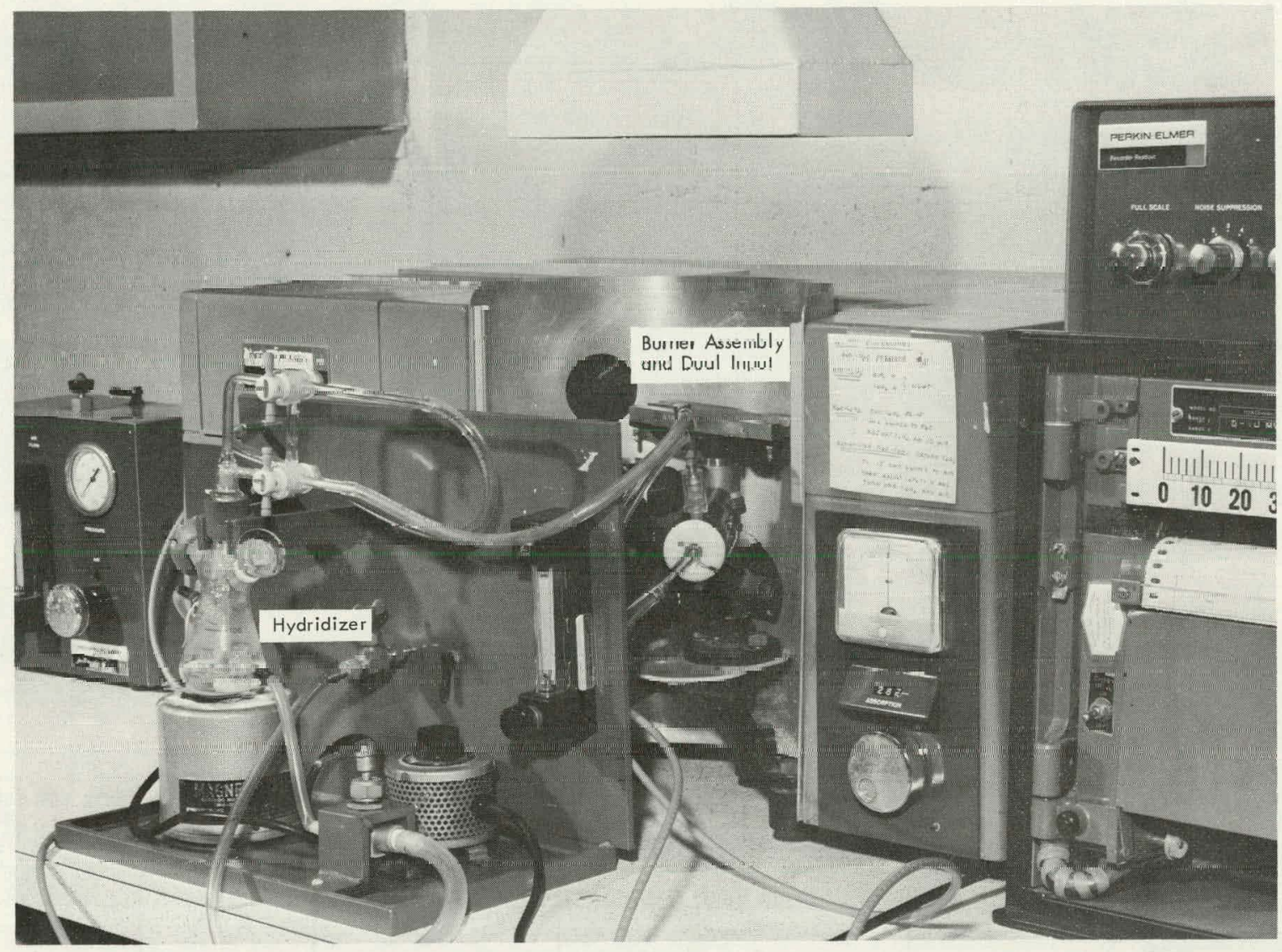

155173

Figure 1. INSTRUMENTATION FOR THE DETERMINATION OF ARSENIC AND SELENIUM IN ENVIRONMENTAL WATER.

usually available in the laboratory contains 0.001 to $0.002 \mathrm{ppm}$ arsenic and faint traces of selenium. A small laboratory demineralizer reduces this contamination by a factor of about 2.

Since the flame-gas flow rates and pressures are very carefully controlled, it is difficult to detect arsenic and selenium responses due to contaminants in the gases. An increase in the hydrogen flow rate increases the flame background, but an increase in the argon flow rate reduces it, as should be expected. Hence, there are no serious problems encountered in gas contamination.

\section{General Considerations}

Hydriding of both arsenic and selenium is accomplished by the hydrogen generated in acid solutions from the reaction:

$$
\mathrm{NaBH}_{4}+\mathrm{HCl}+3 \mathrm{H}_{2} \mathrm{O} \rightarrow \mathrm{NaCl}+\mathrm{H}_{3} \mathrm{BO}_{3}+4 \mathrm{H}_{2} \uparrow
$$

which is postulated as the resultant of the inner reactions:

$$
\begin{gathered}
2 \mathrm{NaBH}_{4}+2 \mathrm{HCl} \rightarrow \mathrm{B}_{2} \mathrm{H}_{6}+2 \mathrm{NaCl}+2 \mathrm{H}_{2} \text {, and } \\
\mathrm{B}_{2} \mathrm{H}_{6}+3 \mathrm{H}_{2} \mathrm{O} \rightarrow 2 \mathrm{H}_{3} \mathrm{BO}_{3}+3 \mathrm{H}_{2} \text {. }
\end{gathered}
$$




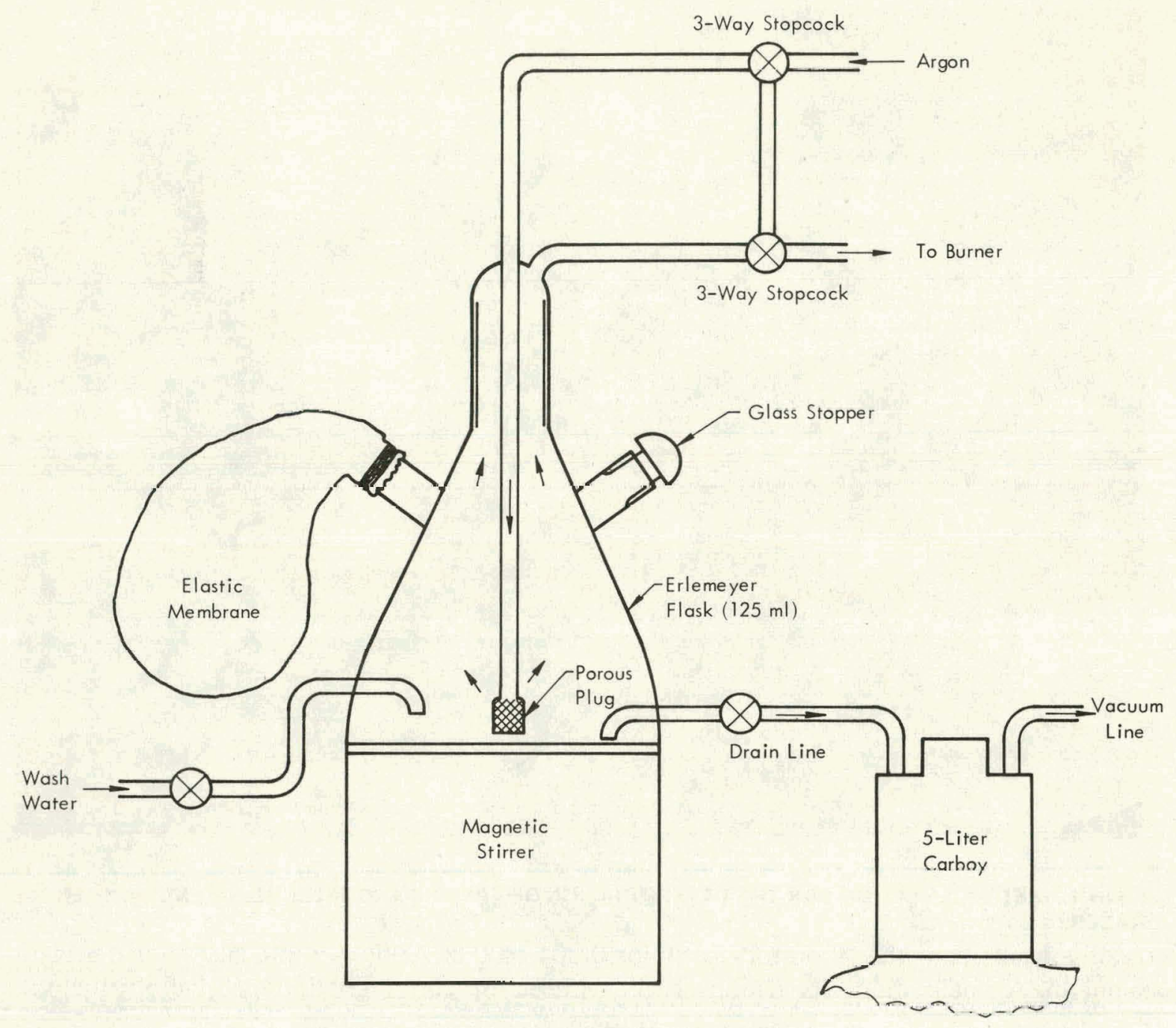

Figure 2. THE HYDRIDING GENERATOR.

On the other hand, in neutral solutions the reaction is:

$$
2 \mathrm{NaBH}_{4}+\mathrm{H}_{2} \mathrm{O} \rightarrow \mathrm{B}_{2} \mathrm{H}_{6} \uparrow+2 \mathrm{NaOH}+2 \mathrm{H}_{2} \uparrow
$$

The reaction proceeds vigorously in acid solutions, while the reaction is relatively slow in a neutral solution. Therefore, it is necessary to use two approaches to generate the analyte gases. One approach is to use the continuous flow of $\mathrm{AsH}_{3}$ and $\mathrm{H}_{2} \mathrm{Se}$ from the generator to produce a continuous integratable signal and the other is to use the accumulation of the generator gas which can be released in a short time period ( 2 to 3 seconds). Both the continuous- and pulse-flow methods have advantages and disadvantages which are discussed the the subsection to follow.

The Continuous-Flow Method-The continuous-flow method, as developed, proceeds as follows: The hydriding generator is prepared by inserting the bubbler in the center neck, placing a septum in one of the remaining two necks, and stoppering the third opening. A solution consisting of $100 \mathrm{ml}$ of $5 \% \mathrm{NaBH}_{4}$ is poured into the generator through the 
stoppered opeing. Ten milliliters of neutralized sample are added with a syringe through the septum, the bubbler is turned on, and the argon flush gas admitted until the recorder response is complete (a period of 45 to 80 seconds). A graphic integration of the response is compared to responses from standards to obtain the result. Instrument, gas flow, and flame parameters are listed in Table 1.

The Gas-Pulse Method-The gas-pulse method is as follows: The hydriding generator is fitted with an elastic membrane on the otherwise stoppered glass neck. The septum is removed and a special glass stopper, designed to contain a $0.2-\mathrm{g}$ $\mathrm{NaBH}_{4}$ pellet, is substituted. A $20-\mathrm{ml}$ water sample is acidified with distilled $\mathrm{HCl}$ (20 $\mathrm{ml}$ for selenium and $4 \mathrm{ml}$ for arsenic) and transferred to the hydriding chamber (after dilution to $40 \mathrm{ml}$ in the case of arsenic). The magnetic stirrer is turned on and argon is flushed through the hydrider and sample for three seconds to remove the air. $\mathrm{NaBH}_{4}$ is then dropped into the sample solution. After an interval of 30 seconds, the argon-flush-gas valves are opened and the pulse response recorded on the recorder. Instrument, flow gas, and flame parameters are listed in Table 1.

\section{RESULTS AND DISCUSSION}

Typical responses for both the continuous-flow and gas-pulse methods for the element arsenic are illustrated in Figure 3. The difference in the 0.025 and $0.05-\mathrm{ppm}$ responses in the continuous-flow method is significant, but small. Since the gas does not accumulate, no time control is needed. In the gas-pulse approach, the fast response appears to be essentially linear in relation to concentration, but the accumulation time must be controlled carefully. The gas-pulse technique was determined to be more satisfactory for the procedure than the continuous-flow method. Calibration curves for arsenic and selenium are plotted in Figures 4 and 5. Results and precision evaluations obtained for two levels of arsenic and selenium are presented in Tables 2 and 3. These precisions are, for the present time, quite satisfactory.

Clearly, one advantage of the gas-pulse application is that the noise increment is relatively small, due to the fact that the signal is generated very quickly and, thus, the spectral-lamp variation and instrument fluctuation are seen for perhaps two to three seconds. In the continuous-flow technique, a small signal and the same instrument and lamp noises are seen over a period of 60 seconds or more. The effect can be expressed mathematically as:

$$
Z_{1}=\frac{R}{\int_{0}^{3} U d t} \quad \text { for the gas-pulse method, and }
$$




$$
Z_{2}=\frac{\int_{0}^{60} r d t}{\int_{0}^{60} U d t} \quad \text { for the continuous-flow method, }
$$

where:

$Z_{1.2}$ represent the signal-to-noise ratios,

R the signal generated by the gas pulse,

Udt the noise at time ( $t)$, and

$r \quad$ the signal at any time $(t)$ during continuous flow.

The time required for the response from the pulse is 3 to 4 seconds, and the total analyte is injected in this time period. About 50 seconds are required to continuously pass the analyte into the burner; thus, there is a concentration of a factor of 10 in the gas-pulse method.

Importance of the control of noise and/or background should be emphasized. Fernandez(d) reports a heavy background arising from the burst of hydrogen which enters the flame on flushing, and describes the use of a background corrector in his work. It is suggested that at least past of the background observed is actually a signal from contaminants and part of it is the result of high gas-flow rates. It is not too difficult to work without a background corrector when certain considerations are made.' A rigorous analysis of the gas-flow mechanisms (which involves the dual input for the fuel and flush gases, the diluting argon gas, and the aspirated air through the capillary) is beyond the scope of this report. However, if one considers, in a very simple way, the dual entry port through which the fuel and flush gases enter, an interaction between the two flows can be seen.

There are two flow states in the dual port, both of which are in a steady-state condition and occur in both the fuel input and flush input. State 1 exists during the time when the hydrider is bypassed; State 2 exists during the flush period. At the point where the two gases combine in the port (C), there exists a pressure, $P$ (see Figure 6). According to the Euler formula:

$$
\rho R d R+d P_{c}=0
$$

where:

$$
\begin{aligned}
& \rho \quad \text { represents the density, } \\
& \mathrm{R} \text { the velocity, and } \\
& \left.P_{C} \text { the pressure at Point } C \text { ( } \Gamma \text {-igure } 6\right) \text {. }
\end{aligned}
$$

In State 2, when the argon flush gas is passing through the hydrider, a slight drop occurs in the argon gas velocity due to the porous plug in the apparatus. This restriction, in turn, causes a pressue increase of $\Delta \mathrm{P}_{\mathrm{C}}$ at Point $\mathrm{C}$. From Equation 7 it can be seen that the left-hand 


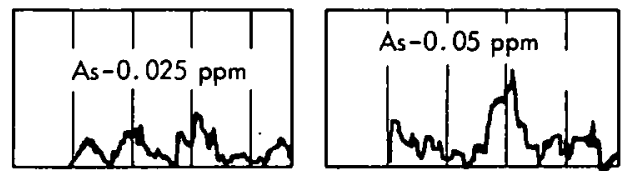

(a) Continuous-Flow Method.

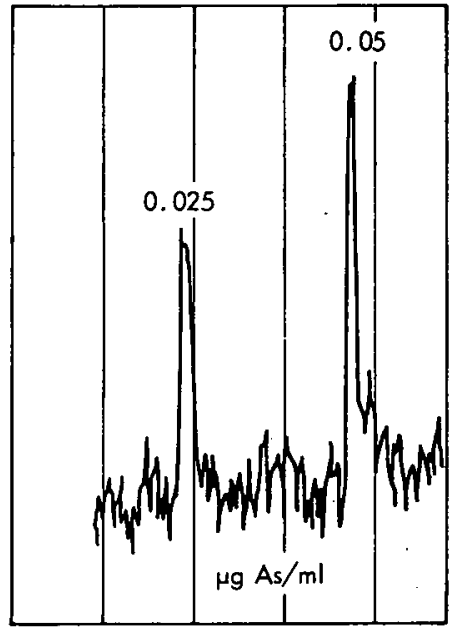

(b) Gas-Pulse Method.

Figure 3. TYPICAL ARSENIC RESPONSES.

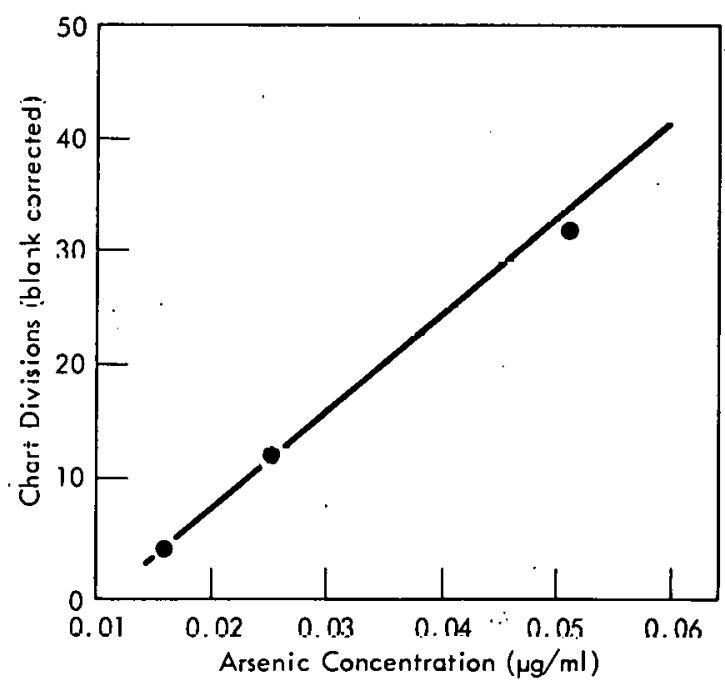

Figure 4. TYPICAL CALIBRATION CURVE. (Arsenic in Environmental Water)
Table 2

PRECISION EVALUATIONS FOR ARSENIC

\begin{tabular}{lcc}
\hline Day & $0.05 \mu \mathrm{g} / \mathrm{ml}$ Level & $0.10 \mu \mathrm{g} / \mathrm{ml}$ Level \\
\hline 1 & 0.052 & 0.10 \\
& 0.050 & 0.12 \\
& 0.052 & 0.10 \\
& 0.048 & 0.11 \\
& 0.055 & 0.10 \\
& 0.048 & 0.11 \\
2 & 0.052 & 0.11 \\
& 0.050 & 0.13 \\
& 0.050 & 0.11 \\
& 0.048 & 0.10 \\
Mean & 0.052 & 0.009 \\
LE $_{X}$ Absolute & 0.048 & 0.009 \\
LE $_{X-2}$ Absolute & $\pm 0.050_{4}$ & $0.10_{6}$ \\
LE $_{X-2}$ Relative & \pm 0.0035 & 0.026 \\
\hline
\end{tabular}

(1) Absolute limit of error for a single measurement at $95 \%$ confidence.

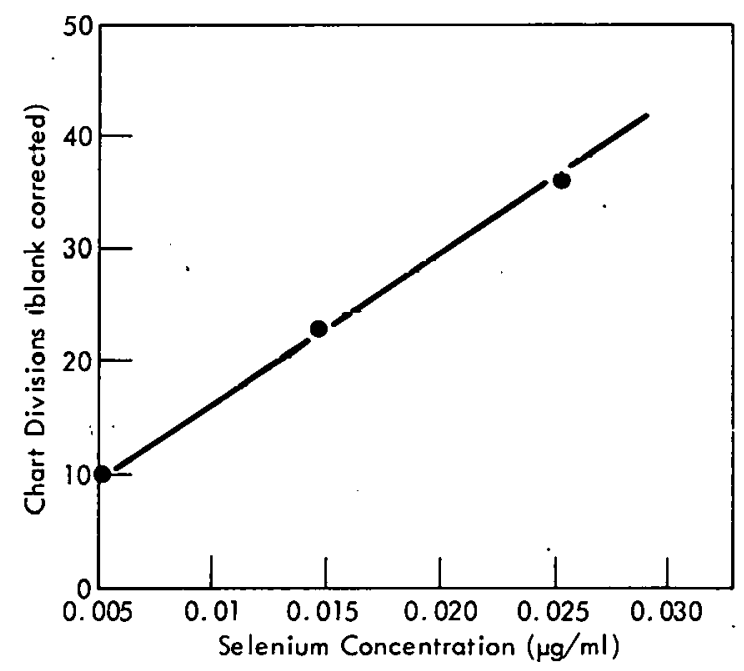

Figure 5. TYPICAL CALIBRATION CURVE. (Selenium in Environmental Water) 
Table 3

PRECISION EVALUA-IONS FOR SELENIUM

\begin{tabular}{|c|c|c|}
\hline Day & $0.010 \mu \mathrm{g} / \mathrm{ml}$ Level & $0.02 \mu \mathrm{g} / \mathrm{ml}$ Level \\
\hline 1 & 0010 & 0.020 \\
\hline 2 & 0010 & 0.020 \\
\hline 3 & 0.011 & 0.023 \\
\hline 4 & 0.010 & 0.022 \\
\hline 5 & 0.011 & 0.020 \\
\hline 6 & 0.011 & 0.019 \\
\hline 7 & 0.009 & 0.018 \\
\hline $8 \cdot$ & 0.010 & 0.019 \\
\hline 9 & 0.010 & 0.018 \\
\hline 10 & 0.012 & 0.019 \\
\hline 11 & 0.010 & 0.017 \\
\hline 12 & 0.012 & 0.019 \\
\hline 13 & & 0.020 \\
\hline 14 & & 0.020 \\
\hline 15 & & 0.022 \\
\hline 16 & & 0.020 \\
\hline Mean & 0.3105 & 0.020 \\
\hline LE $_{x}$ Absolute ${ }^{(1)}$ & \pm 0.302 & \pm 0.0033 \\
\hline $\mathrm{LE}_{x-2}$ Absolute & \pm 0.3014 & \pm 0.0024 \\
\hline LE $_{x-2}$ Relative & \pm 14 & \pm 12 \\
\hline
\end{tabular}

(1) Absolute limit of error for a single measurement at 95\% confidence.

Figure 6. DUAL FEED DEVICE SHOWING GAS-FLOW INTERACTIONS. 
quantity must now decrease, or rather the hydrogen flow must now decrease. It is apparent that the dual port is functioning as a gas aspirator. Without going into the effects of the membrane collapse during flush, one can see that the proper flush-gas flow can reduce the fuel rate to compensate for the hydrogen input from the generator into the flame. To do this, the flush-gas flow rate is set at a nominal value during bypass, with only water in the closed hydrider and the flame running. The recorder is turned on and set downscale. The flush gas is then sent through the hydrider and the change in background is noted. If a small negative response is observed ( 1 or 2 chart divisions) the system is compensating; if the response is not observed, the flush-gas flow is increased slightly until the base line decreases by a slight amount. It is recommended that a small ( 3 to 5 chart divisions) blank be observed at the start of operations. When the flush gas is set properly, the instrument "sees" nothing new during the flush except the hydrides of arsenic and selenium. Passing the lamp flux through the flame ( $8 \mathrm{~mm}$ above the burner slots) also improves the background.

Other implications of the analytical procedures described in this report are that there is a possible application to phosphorus determination using an air/hydrogen flame and use of the generator gases to reduce oxidation effects in flames. 


\section{DISTRIBUTION}

Atomic Energy Commission - Oak Ridge

Hickman, H. D.

Zachry, D. S., Jr

Oak Ridge Gaseous Diffusion Plant

Wilcox, W. J., Jr

Winkel, R. A.

\section{Oak Ridge Y-12 Plant}

Barringer, R. E.

Bernander, N. K.

Briscoe, O.W.

Burditt, R. B.

Burkhart, L: E.

Charles, J. W.

Denny, A.

Ebert, T. H.

Fraser, R. J.

Keith, A.

King, H. G. (10)

Kite, H. T.

Lundin, M. I.

Marrow, G. B.

MeLendôn, J. D.

Morrow, R. W.

Neff, C. M.

Phillips, L. H.

Rowan, J. H.

Schreyer, J. M.

Smith, R. D.

Thomason, J, C.

Weathersby, W. E.

Yayyi, W. J./Googin, J. M.

Y.12 Central Files (5)

$Y-12$ Central Files (master copy)

Y.12 Central Files (route copy)

$Y-12$ rentral Files $(Y=12 R C)$

\section{Paducah Gaseous Diffusion Plant}

Levin, R. W.

In addition, this report is distributed in accordance with the category UC-4, Chemistry, as given in the USAEC Standard Distribution Lists for Unclassified Scientific and Technical Reports, TID-4500. 